\title{
PELE, ÓRGÃOS E PENSAMENTOS DE UM CORPO-PROFESSOR: TRAÇOS INICIAIS DE UMA INTENÇÃO DE PESQUISA
}

Marcelo Feldhaus ${ }^{1}$

\section{Resumo}

O presente texto integra a intenção de pesquisa de meu doutoramento que visa promover reflexões acerca da imagem da escola e do ensino da arte na atualidade como campo expandido, enquanto corpo orgânico de potência que constrói formas de vida, modos de existência nas dimensões ética, estética e política. Os traços desta escrita desenham-se como um conjunto de intenções de um corpo-professor e é reflexo dos registros descritos em meu memorial descritivo e anteprojeto de tese apresentados durante o processo seletivo do Programa de Pós-Graduação da UFRGS, no primeiro semestre de 2017. Interessa-me pensar, enquanto método, a pesquisa educacional baseada em arte a a/r/tografia, que propõe formas de escrita para além da palavra, pensando a imagem enquanto texto, potência carregadas de visibilidades e invisibilidades aparentes.

Palavras-chave: pesquisa em arte; corpo-professor; metodologia; a/r/tografia.

\section{SKIN, ORGANS AND THOUGHTS OF A TEACHER-BODY: INITIAL TRAITS OF A RESEARCH PURPOSE}

\section{Abstract}

This text is a research purpose of my doctoral degree that aims at reflecting on school and Arts teaching images as an extended field nowadays, while an organic body with power, which builds ways of life and ways of existence in ethical, aesthetics and political dimensions. Traits of this writing become a group of intentions of a body-teacher and it replicates registers, descripted in my descriptive memorial and my thesis project, presented during the entrance process at UFRGS Postgraduation Program, in the first semester of 2017 . The method is a/r/tography, a kind of educational research based in Arts that purposes ways of writing beyond word, admitting images as text, potencies plenty of visibilities and invisibilities.

Keywords: research in Arts; teacher-body; methodology; a/r/tography

\footnotetext{
${ }^{1}$ Doutorando do Programa de Pós-Graduação em Educação, linha de Arte, Linguagem e Currículo da Universidade Federal do Rio Grande do Sul - UFRGS; Membro do Grupo de Pesquisa em Arte GPA da Universidade do Extremo Sul Catarinense - UNESC. E-mail: profmarcelo@unesc.net

Criar Educação, Criciúma, v. 7, no1, jan/jul 2018.- PPGE - UNESC
} 


\section{Traços Iniciais}

Já há algum tempo tem se falado e escrito sobre corpo, arte, escola e formação de professores. De tal maneira que poderíamos nos perguntar se há algo novo a ser dito. Afinal, parece que os temas têm se estabelecido com tal obviedade no cenário contemporâneo que nossa tarefa enquanto sujeitos pesquisadores, seria, antes de reforçar a sua evidência, a de desevidenciá-los. Devolver-lhe alguma surpresa, e como propõe Fischer "[...] textos mais vibrantes, mais vivos, mais mobilizadores de nós mesmos e daqueles que nos leem". (2005, p.118)

É nesse contexto que meu interesse pesquisa volta-se, nesse início de doutoramento, volta-se ao que denomino como corpos-professores-escolas, no sentido de olhar para as imagens da escola, presentes nas escolas e seus corpos, como campos de investigação compreendendo-os como campos expandidos de formação.

Pensando nestas questões, o corpo parece ter ficado fora da escola, isto é, despercebido na maioria das teorias educacionais e também nos cursos de formação inicial e continuada de professores (percepção a partir de minhas experiências como aluno, professor e gestor), uma invisibilidade tão consistente quanto se dão as invisibilidades ideológicas outras. No campo da educação, não apenas separamos corpo e mente, mas desconfiamos do corpo. É visível nas universidades e nas escolas a preocupação com ideias e conceitos, que parecem vir de seres sem corpo. Meu interesse de doutoramento se desenha para além do corpo como conceito biológico, mas o corpo-escola, como campos do possível ${ }^{2}$, de desvios, expansão, transformação, resistência (Imagem 01).

\footnotetext{
${ }^{2}$ HONORATO, 2015

Criar Educação, Criciúma, v. 7, no1, jan/jul 2018.- PPGE - UNESC
} 
Voltados para um dos grandes desafios da educação brasileira, que é a formação de professores, diversos pesquisadores debruçam-se sobre esse tema, fato que pode ser comprovado em pesquisas disponíveis no banco de teses e dissertações da Capes, entendendo que processos de qualificação e incentivo na formação dos professores refletirá numa maior qualidade na educação de meninos e meninas com os quais trabalham. Partindo deste pressuposto, me pergunto: de que forma podemos pensar a imagem da escola e do ensino da arte na atualidade, enquanto corpo orgânico de potência que constrói formas de vida, modos de existência nas dimensões ética, estética e política?

Pensando a partir de Foucault que "onde existe poder, existe resistência" como pensar um corpo-escola (docência, aluno, arte, ensino da arte) que se reinventa, faz desvios, faz sentido às tensionalidades do poder tomando como referência o ensino da arte e a própria arte como existência de si?

Pretendo desenvolver minha investigação a partir de um recorte histórico (1996-2016), que se justifica pela promulgação da LDB 9394-96, a qual prevê a obrigatoriedade do ensino da arte nas diferentes etapas da Educação Básica. Após duas décadas de propulsão na formação inicial e continuada de professores e professoras de Artes, que expansões, fronteiras, amarras e desafios ainda se fazem presentes no corpo-professor? Que arte está presente nas escolas? Que conceito de experiência estética embriagam os corpos-professores-escolas? ${ }^{6}$ Que distância existe entre o corpo-arte-escola e o corpo-arte-vida? É possível propor estas separações, pensando nos estudos foucaultianos de escritas de si e estética e ética da existência? Como resistir a presente ameaça da retirada da arte como componente curricular obrigatório a partir da MP 746 de 2016? Como pensar a formação integral, conceito presente nos Projetos Pedagógicos de escolas e universidades sem considerar a presença da arte neste processo? Estaria ainda presente nas escolas investigadas um corpo canônico, genial, distante da vida? Que espaços há para a arte contemporânea (como aproximação da vida) na escola?

\footnotetext{
${ }^{5}$ FOUCAULT, 1999, p.91

${ }^{6}$ Conceito que pretendo aprofundar nos estudos da tese pensando em suas imbricações.

Criar Educação, Criciúma, v. 7, n1, jan/jul 2018.- PPGE - UNESC
} 


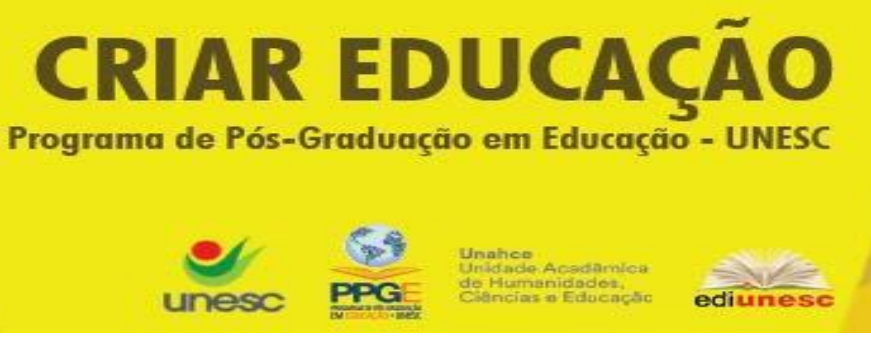

Outro aspecto continua a me inquietar, e, ao mesmo tempo, a me impulsionar: a atuação como professor formador de futuros professores. Como posso contribuir para efetivas mudanças no ensino da arte, na formação desses novos professores, pensando em uma relação orgânica entre universidade e educação básica? Que distâncias há entre a escola e a arte? Como os currículos dos cursos de Artes Visuais corroboram nestas questões?

São muitas as indagações e, certamente, no decorrer da pesquisa, alguns recortes se farão necessários, muito embora essas inquietações dão corpo e substância à discussão que ora se propõe.

\section{A Escolha Das Rotas}

Interessa-me pensar, enquanto possível método, a pesquisa educacional baseada em arte a a/r/tografia ${ }^{7}$, que propõe formas de escrita para além da palavra, pensando a imagem enquanto texto, potência carregadas de visibilidades e invisibilidades aparentes. Proponho pensar o papel do corpo-escola-arte presente em narrativas da docência como campo expandido, olhando a noção de sujeito como perspectiva de geração de um novo conhecimento, "o sujeito performativo, que se constrói de forma fragmentada e descentrada." fala a partir de si mesmo e não de si mesmo promovendo encontros e dissonâncias na produção de uma escritura performativa que se transforma em um recurso por meio do qual se cria ou recria a experiência, em que o corpo (pesquisador, escola, docência e arte) se encontra inserido e, na sua relação com os outros, na perspectiva de poéticas etnográficas ${ }^{9}$. A ideia é olhar para as escolas públicas de Criciúma, seus professores e professoras de Artes, seus corpos visíveis e indizíveis, na perspectiva de uma docência como campo expandido. Olhar a formação e a escola pelos prismas das imagens de escolas e nas escolas, tomando-as como base da pesquisa de campo. Percebo como horizonte possível para isso a arte

\footnotetext{
${ }^{7}$ DIAS, 2013

${ }^{8}$ HERNÁNDEZ, 2013, p.53

9 " (...) que tem objetivos similares aos objetivos da arte: desejam tocar o espectador, evocar emoções e proporcionar perspectivas alternativas de ver o mundo" (DENZIN, 1997 apud HERNÁNDEZ, 2013, p.53)

Criar Educação, Criciúma, v. 7, no1, jan/jul 2018.- PPGE - UNESC
} 
contemporânea, como encontros de dissonâncias. Ela pede ao espectador que pense e ajude-a a criar sentidos, deixa de representar para apresentar. Abre/expõe conflitos políticos e conflitos estéticos aproximados de uma "ética de si" (FOUCAULT, 2010).

Diferenciando-se, portanto de métodos tradicionais de fazer pesquisa, a a/r/tografia se apropria de maneiras alternativas para produzir conhecimento, indo além do que já é feito nos outros modelos, inclusive para que isso ocorra, a a/r/tografia privilegia tanto a linguagem escrita, quanto a visual, construindo desta forma uma pesquisa híbrida, mestiça, cujos conhecimentos, oriundos de formas tão distintas, confluem-se.

Observa-se em publicações de pesquisadores, professores e alunos da área de arte, na academia, que suas escritas ainda seguem acriticamente um modelo positivista (HONORATO, 2015). Esta constatação tem feito muitos pesquisadores das universidades brasileiras, que trabalham na formação de profissionais da área da arte, buscarem caminhos de ruptura com os modos estabelecidos de se fazer pesquisa, pois em oposição ao positivismo estes pesquisadores buscam apontar que o domínio social e cultural demonstra ser um agente basilar na construção do conhecimento. Desta maneira não se pode apenas adaptar os métodos das ciências e considerá-los como única regra para produção e circulação do conhecimento.

Nesse contexto, buscarei estruturar as formas de pensamento presentes na tessitura da tese ancorada e apresentada por imagens, imagens estas que evidenciem o corpo-escola-professor/professora-arte.

\section{O Escopo Teórico}

Para fundamentar minha pesquisa, realizarei estudos com autores que me ajudam a pensar as teorias e conceitos que configurarão o mapa de minha tese, trago abaixo uma síntese de intenções para as discussões teóricas com as quais eles se vinculam, evidenciando assim minhas escolhas. 
Nesse aspecto encontro eco no texto "Escrita acadêmica: arte de assinar o que se lê" da professora doutora Rosa Maria Bueno Fischer, quando nos destaca que,

Reescrever um autor, apropriar-se dele, é vasculhar em suas formulações teóricas um ponto de encontro com nós mesmos, com aquilo que escolhemos como objeto, com aquilo em que nós investimos em nossa vida, nosso trabalho, nosso pensamento; tem a ver com uma entrega, nossa entrega a um tema, a um objeto, a um modo de pensar, que assumimos como pesquisadores. $(2005$, p.120)

É nesse escopo que inicialmente debruço-me nos escritos de Michel Foucault. O corpo aparece nos estudos foucaultianos como uma composição de forças que se encontram em permanente tensionamento. Para Foucault as concepções de corpo não se limitam a conceitos orgânicos, previamente, se apresentam como um campo sobre o qual operam diferentes dispositivos. $O$ corpo não deve ser pensando a partir de uma existência a priori, e sim como um objeto que deve ser problematizado, investido por forças e, por fim, produzido.

As pesquisas de Giorgio Agamben contribuirão nessa pesquisa a partir da discussão colocada pelo autor sobre a fragilidade do homem em relação aos processos da experiência.

Jorge Larrosa, Gilles Deleuze, Jacques Rancière, Nietzsche, Fernando Hernandez, dentre outros, são colocados aqui como campos de aprofundamento teórico, cada um resguardado a sua particularidade investigativa (Imagem 02).

Trabalhar com autores, especialmente com Foucault, é diferente de aplicar os autores em nossas pesquisas,

Pois trabalhar com um autor é, em primeiro lugar, fazer todas as leituras possíveis de seus textos, estudá-los seriamente, traduzi-los para si mesmo, falar deles, expor as dúvidas e as iluminações aos colegas, não temer inclusive publicar ideias e ensaios de "incorporação" (FISCHER, 1996, p.39)

Esse é um dos principais objetivos desse ensaio, um exercício de "incorporação", como sugere a autora, um arriscar-se em leituras, devaneios, iluminações e reflexões profundas que se repetem duas, três..., inúmeras vezes, até 


\section{CRIAR EDUCAÇÃO}

Revista do Programa de Pós-Graduação em Educação - UNESC

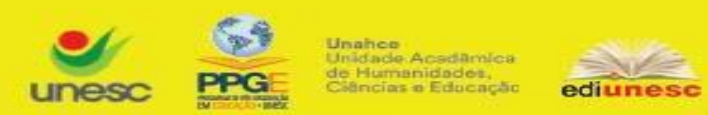

nos embriagarmos com as concepções do autor, de certa forma continuando sua obra. O objeto de pesquisa que nos move, nos instiga e nos apaixona, ultrapassa os objetos escolhidos pelo autor, justamente porque "nossa história é outra, nossos lugares, e tempo são outros" (FISCHER, 1996, p.120).

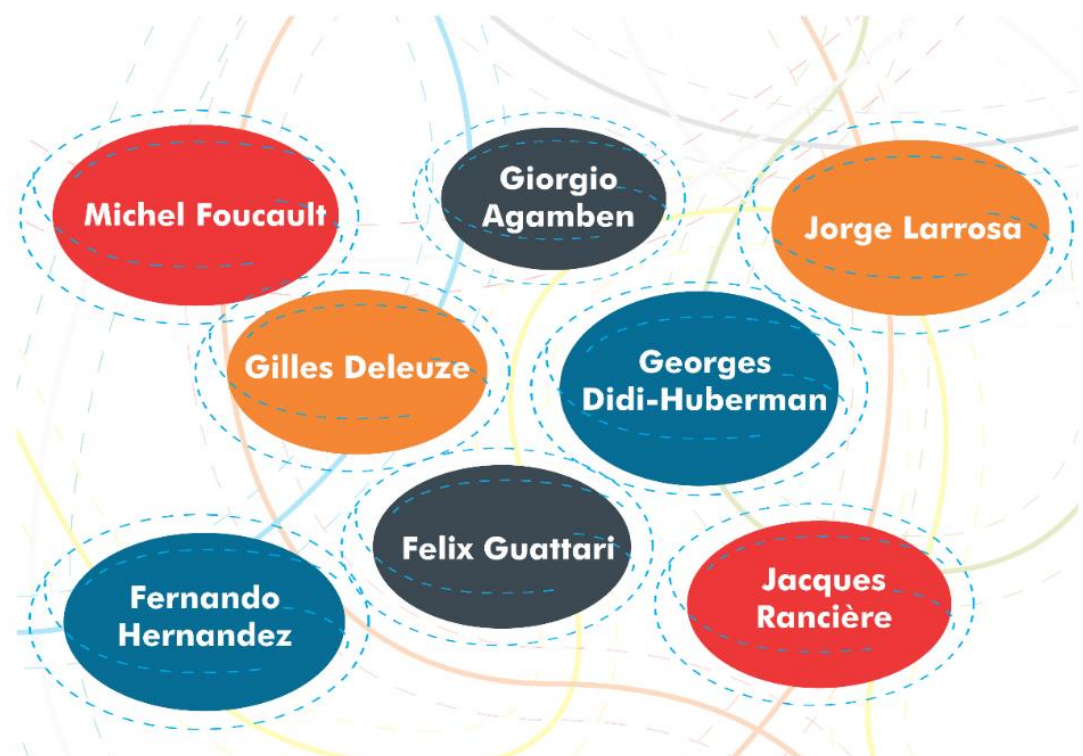

Imagem 02 - Escopo teórico inicial, 2017

Fonte: Acervo do pesquisador

Dentre meus referenciais artísticos, elejo nesta escrita, para problematizar estas questões, o encontro com as produções da artista Cinthia Marcelle ${ }^{10}$. A artista propõe em suas produções a observação atenta da arte presente no cotidiano. Poderia aqui aproximar sua produção, feitas as devidas reservas, nos estudos realizados por Foucault e Nietszche tendo a vida como obra de arte.

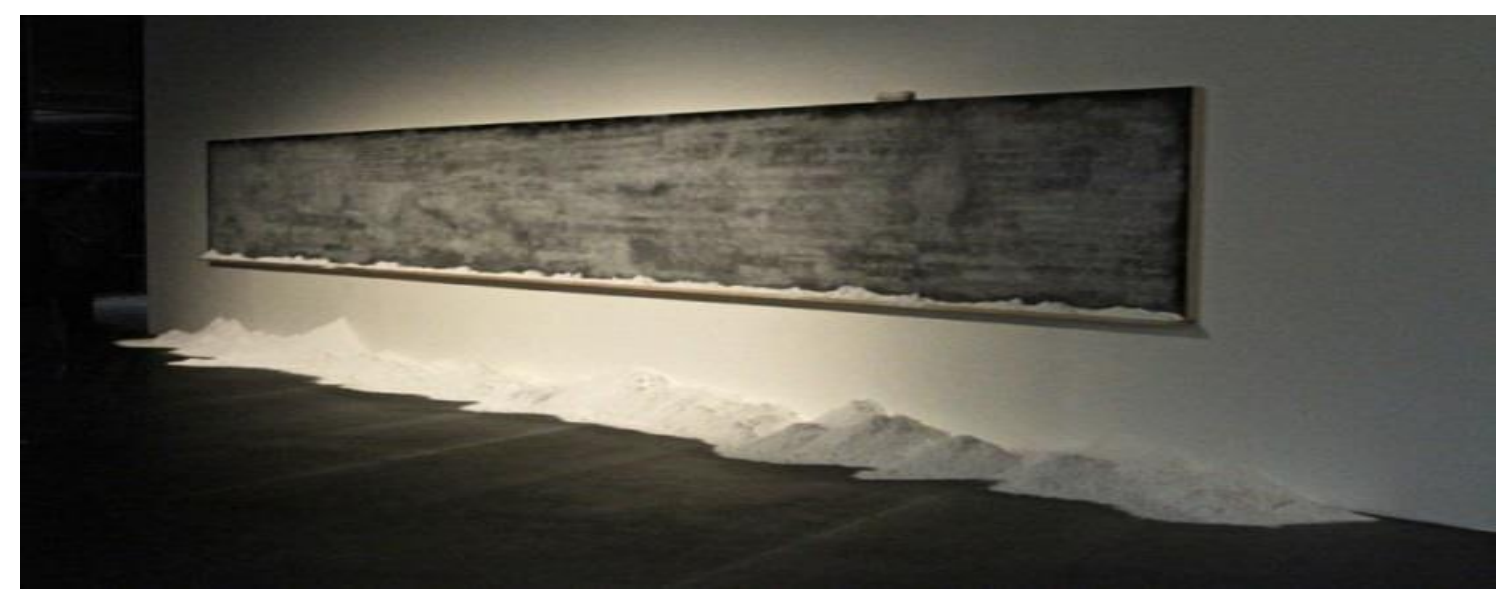

${ }^{10}$ Disponível em: https://www.ufrgs.br/arteversa/?p=970

Criar Educação, Criciúma, v. 7, no1, jan/jul 2018.- PPGE - UNESC 


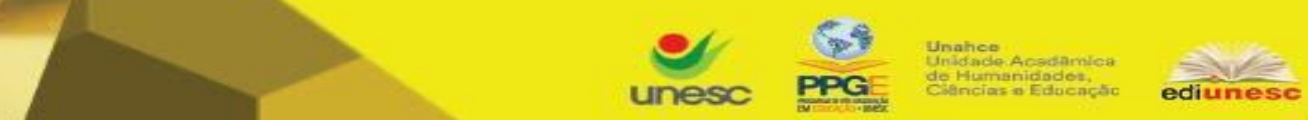

Imagem 03 - Sobre este mundo, 2010

Fonte: https://www.ufrgs.br/arteversa/?p=970
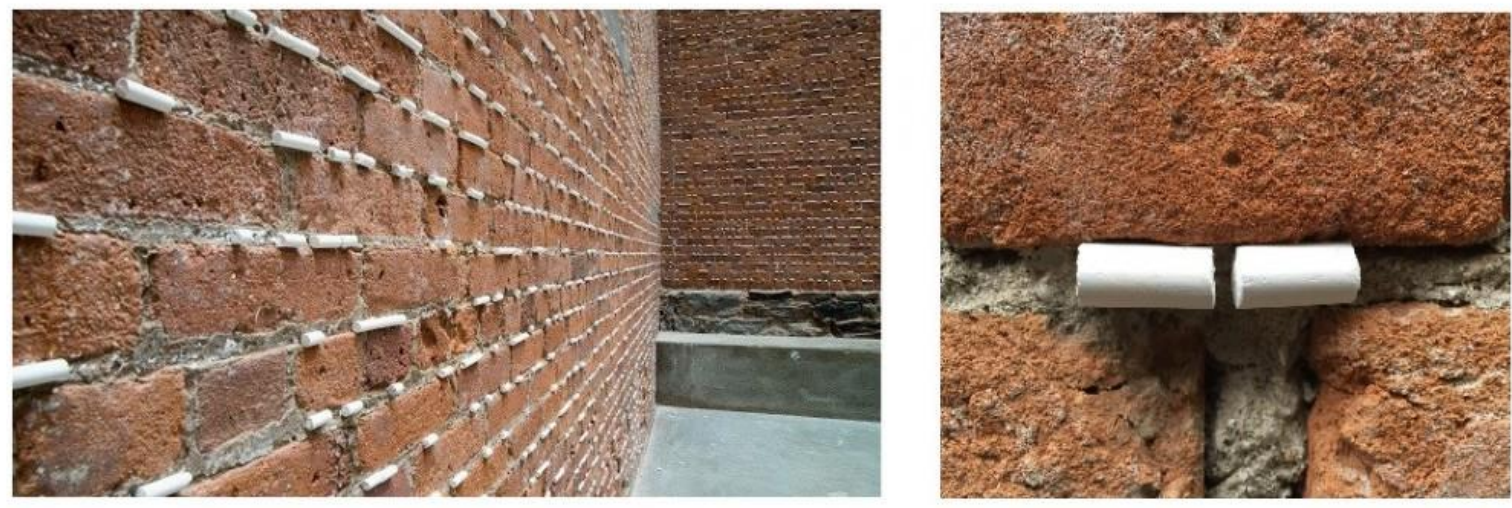

Imagem 04 - Educação pela pedra, 2016

Fonte: https://www.ufrgs.br/arteversa/?p=970

A artista justapõe, traz resíduos, encontra a poeira (imagem 03), faz pensar na ideia de corpo-escola-arte e formação de professores pelo viés da Arte Contemporânea. Suas imagens criam espaços de entrelugares ${ }^{11}$, representados pelo "pó de giz e seus resquícios no quadro negro que logo serão esquecidos e levados como poeira". O giz também protagoniza outro trabalho, quando o coloca como sustentação de cadeiras e apoio de paredes. Ele, um dos materiais mais simples presentes no corpo escola é mostrado como objeto principal de sua produção (imagem 04).

São ressonâncias que me fazem acreditar que a arte está no meio da vida e que com ela podemos problematizar a escola e seus atores sobre diferentes prismas. A arte que persigo propõe encontros, deslizamentos, recuos, avanços. Que sai do acostamento e ganha a via principal, a autoestrada que se faz no exercício diário de uma estética da existência.

\footnotetext{
${ }^{11}$ Ver Didi-Huberman, 1999

Criar Educação, Criciúma, v. 7, no1, jan/jul 2018.- PPGE - UNESC
} 
Encontro então no Programa da FACED - Faculdade de Educação, Programa de Pós-Graduação em Educação, linha de Arte Linguagem e Currículo, mais precisamente nas pesquisas desenvolvidas pelo grupo ArteVersa ${ }^{12}$ liderado pela professora Dra. Luciana Gruppelli Loponte, minha professora orientadora, a possibilidade de expandir meus anseios e interesses de pesquisa no campo da docência como escrita de si, da escola como equipamento de disciplina amparados nas problemáticas estudadas pelo grupo, bem como nos estudos de Foucault e Nietzsche.

As questões propostas pelo grupo criam eco em meus anseios de professor formador e pesquisador, ou somente de professor. E nesse movimento de ir e vir, tirar e compor camadas, construir a ética e a estética de si, entender as subjetividades do ser professor, me aventuro e encorajo - com o devido cuidado e responsabilidade necessárias a um processo de postulado ao doutorado.

\section{Algumas Considerações - Iniciais}

Conforme destacado no início desse texto, as ideias aqui apresentadas constituem-se em minhas intenções para a pesquisa de doutoramento, iniciado em agosto de 2017.

O desenvolvimento das aulas/disciplinas e o aprofundamento dos estudos, orientações, abrirão novos caminhos e percursos possíveis na composição da tese. No entanto, é importante destacar que o que move meus anseios de professorpesquisador é debruçar-me nas relações corpo-escola-arte-professor, entendendo este composto como campo expandido, na escola como espaços do possível, de devires, transformação, uma pesquisa colaborativa, de reflexividade, em que me construo no outro, com o outro e em relação aos outros.

Pensar outros de compreender a arte, o professor, a escola, a educação, colocando em suspenso o que acreditamos. Olhar crítica, ética e politicamente por outras vias, impregnar-se na direção de um professor de Artes aberto a "aberturas" em suas aulas, a construir desvios que promovam mudanças de modos de vida.

\footnotetext{
${ }^{12}$ Disponível em: https://www.ufrgs.br/arteversa/?tag=arte-contemporanea

Criar Educação, Criciúma, v. 7, no1, jan/jul 2018.- PPGE - UNESC
} 
Estes espaços se configuram a partir do debate, do caminhar, assim constituindo-se espaços de aprendizagens, espaços de produção do pensar.

Encerro aqui, o que espero ser o prefácio de uma obra que quero construir com os desafios que se descortinam em um processo de doutoramento, não distante da vida e do conhecimento produzido por ela.

\section{Referências:}

AGAMBEN, Giorgio. O que é o contemporâneo? e outros ensaios. Tradução Vinícius Nicastro Honesko. Chapecó: Argos, 2009.

DIAS, Belidson. IRWIN, Rita (org). Pesquisa educacional baseada em arte: a/r/tografia. Santa Maria: Ed. da UFSM, 2013

FISCHER, Rosa Maria Bueno. Escrita acadêmica: arte de assinar o que se lê. In: COSTA, Marisa Vorraber; BUJES, Maria Isabel Edlweiss. (orgs). Caminhos investigativos III: riscos e possibilidades de pesquisar nas fronteiras. Rio de Janeiro: DP\&A, 2005, p. 117-140

FISCHER, Rosa Maria Bueno. A paixão de "trabalhar com" Foucault. In: COSTA, Marisa Vorraber; (org). Caminhos investigativos: novos olhares na pesquisa em educação. Porto Alegre: Mediação, 1996, p.37-60

FOUCAULT, Michel. Literatura e pintura, música e cinema. Ditos \& Escritos III. Rio de Janeiro: Forense Universitária, 2009.

FOUCAULT, Michel. Vigiar e punir: nascimento da prisão. 41 ed. Petrópolis, RJ: Vozes, 2013.

DELEUZE, Gilles. Mil platôs: capitalismo e esquizofrenia 2, vol. 1. Tradução de Ana Lúcia de Oliveira, Aurélio Guerra Neto e Célia Pinto Costa. São Paulo: Editora 34, 1995.

HERMANN, Nadja. Ética e estética: a relação quase esquecida. Porto Alegre: EDIPUCRS, 2005.

LOPONTE, Luciana Gruppelli. Docência artista: arte, estética de si e subjetividades femininas. 2005. 207 f. Tese (Doutorado em Educação) - Faculdade de Educação. Universidade Federal do Rio Grande do Sul, Porto Alegre, 2005.

KRAMER, Sonia. Com a pré-escola nas mãos: uma alternativa curricular para a educação infantil. 6.ed São Paulo: Ática, 1993. 
PELLEJERO, Eduardo. A lição do aluno: uma introdução à obra de Jacques Rancière. Saberes, Natal - RN. v. 02. n.03. dez 2009. p. 18-30.

RANCIÈRE, Jacques. O mestre ignorante: cinco lições sobre a emancipação intelectual. 3 ed. Tradução de Lílian do Valle. Belo Horizonte: Autêntica Editora, 2011. 